\title{
Provitamin $D_{3}$ in Tissues and the Conversion of Cholesterol to 7-Dehydrocholesterol in vivo
}

\author{
By MARY GLOVER, J. GLOVER AND R. A. MORTON \\ Department of Biochemistry, The University of Liverpool
}

(Received 25 April 1951)

The discovery that the absorption bands at 293, 281.5 and $271 \mathrm{~m} \mu$. (Heilbron, Kamm \& Morton, $1926,1927)$ present in fractions obtained in the recrystallization of cholesterol were shown very strongly by ergosterol (Rosenheim \& Webster, 1927) focused interest on the latter and culminated in the isolation of calciferol (vitamin $\mathrm{D}_{\mathbf{2}}$ ). Some time later it was recognized that 7-dehydrocholesterol was a provitamin $D$ and vitamin $D_{3}$ was eventually obtained pure.

Vitamin $D_{3}$ in fact appeared to be the principal, if not the only 'natural', vitamin $D$. With the achievement of commercial production interest in the field declined, although many problems remained unsettled.

Perhaps the most important of these is the biogenesis of provitamin $D$. In the herbivorous animal, the dietary sterols, sitosterol, stigmasterol, etc., are unlikely to be responsible for the appearance of 7 dehydrocholesterol. Ergosterol, which is characteristic of yeasts and fungi, could scarcely account for the wide distribution of provitamin $D_{3}$ in animals.

The present work provides evidence of a reversible enzymic dehydrogenation of cholesterol mainly in the gut wall. The 7-dehydrocholesterol is thus not of dietary origin. It may have biological functions independent of its role as provitamin $\mathrm{D}_{3}$.

\section{EXPERIMENTAL}

General. The scope of the present investigation may be set out as follows: (i) determination of the properties of pure 7-dehydrocholesterol, (ii) the esti- mation of provitamin $D_{3}$ in animal tissues, (iii) distribution of provitamin $D_{3}$ in guinea pig, rat and ox tissues, (iv) a closer study of 7-dehydrocholesterol in the skin and small intestine of the guinea pig, (v) sterol metabolism in the small intestine of the guinea pig and the reversible dehydrogenation of cholesterol.

\section{Methods}

Absorption spectra were determined using a Beckman photoelectric spectrophotometer with spectroscopically pure ethanol as solvent.

Optical rotation measurements were carried out using a $0.5 \%$ solution in the same solvent in a $0.5 \mathrm{dm}$. cell.

Materials. Tissues were obtained from freshly killed rats and guinea pigs. Ox tissues were obtained from the abattoir and were examined without delay.

Cholesterol was recrystallized until it no longer showed the 7-dehydrosteroid absorption bands.

7-Dehydrocholesterol was obtained (approximately $90 \%$ purity) from Peboc Ltd., London, and purified by recrystallization from ethyl acetate. However, after drying over $\mathrm{H}_{2} \mathrm{SO}_{4}$, both the melting point and the optical rotation were low. Further recrystallization from the same solvent, followed by desiccation over $\mathrm{CaCl}_{2}$, gave a product of satisfactory purity (Table 1). The highest absorption occurs at $281.5 \mathrm{~m} \mu$. $\left(E_{1}^{1 \%} \mathrm{~cm} .=308 ; \epsilon_{\max .}=11840\right)$. As will be seen later, it is necessary to rely upon spectrophotometric readings for the determination of 7-dehydrocholesterol, and the most convenient way of describing the absorption spectrum of the pure substance is given in Table 2.

Administration. The sterols were dissolved in warm methyl oleate or myristate, allowed to cool with stirring, and doses of $1 \mathrm{ml}$./animal of the thick suspension were given orally from a pipette with a wide jet; cholesterol $0.25 \mathrm{~g} . / \mathrm{ml}$.; 7-dehydrocholesterol $0 \cdot 2 \mathrm{~g} . / \mathrm{ml}$.

Table 1. Properties of 7-dehydrocholesterol

\begin{tabular}{|c|c|c|c|}
\hline M.p. & Optical rotation & $E_{1}^{1 \%} \%(281.5 \mathrm{~m} \mu)$. & Reference \\
\hline $142-143 \cdot 5^{\circ}$ & $\begin{array}{c}{[\alpha]_{D}^{20^{\circ}}=-113-116^{\circ}} \\
\left(\mathrm{CHCl}_{3}\right)\end{array}$ & - & Windaus, Lettré \& Schenck (1935) \\
\hline $\begin{array}{l}150^{\circ} \\
149-150^{\circ}\end{array}$ & 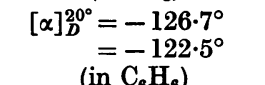 & - & $\begin{array}{l}\text { Boer et al. (1936) } \\
\text { Boer et al. }(1936)\end{array}$ \\
\hline $148-149^{\circ}$ & $\underline{-}$ & 一 & Schenck, Weise \& Buchholz (1936) \\
\hline $126^{\circ}$ & - & 280 & Hogness, Sidwell \& Zscheile (1937) \\
\hline $135-138^{\circ}$ & {$[\alpha]_{D}^{21^{\circ}}=-82^{\circ}$} & 284 & Present authors \\
\hline${ }^{*} 146^{\circ}$ & $\begin{array}{c}{[\alpha]_{D}^{200^{\circ} 5^{\circ}}=-117^{\circ}} \\
\text { (ethanol) }\end{array}$ & $\begin{array}{c}308 \\
\text { (ethanol) }\end{array}$ & Present authors \\
\hline
\end{tabular}


Table 2. Extinction values for 7-dehydrocholesterol $(E)$ expressed as fractions of $E_{\max .}$ at $281.5 \mathrm{~m} \mu$. (in ethanol)

$\begin{array}{cc}\begin{array}{c}\lambda \\ (\mathbf{m} \mu .)\end{array} & E \\ 240 & 0 \cdot 183 \\ 245 & 0 \cdot 225 \\ 250 & 0 \cdot 321 \\ 255 & 0 \cdot 426 \\ 260 & 0 \cdot 608 \\ 262 & 0 \cdot 657 \\ 265 & 0 \cdot 700 \\ 268 & 0 \cdot 823 \\ 270 & 0 \cdot 931 \\ 271 & 0 \cdot 957 \\ 271 \cdot 5 & 0 \cdot 958 \\ 272 & 0 \cdot 951 \\ 273 & 0 \cdot 915 \\ 274 & 0 \cdot 883 \\ 275 & 0 \cdot 855 \\ & * \epsilon_{\text {max. }}=11840 .\end{array}$

\section{Estimation of provitamin $D_{3}$ in tissues}

A weighed portion of tissue is usually saponified directly by refluxing with ethanolic $\mathrm{KOH}$ without preliminary extraction of the lipid fraction. In some cases the absorption

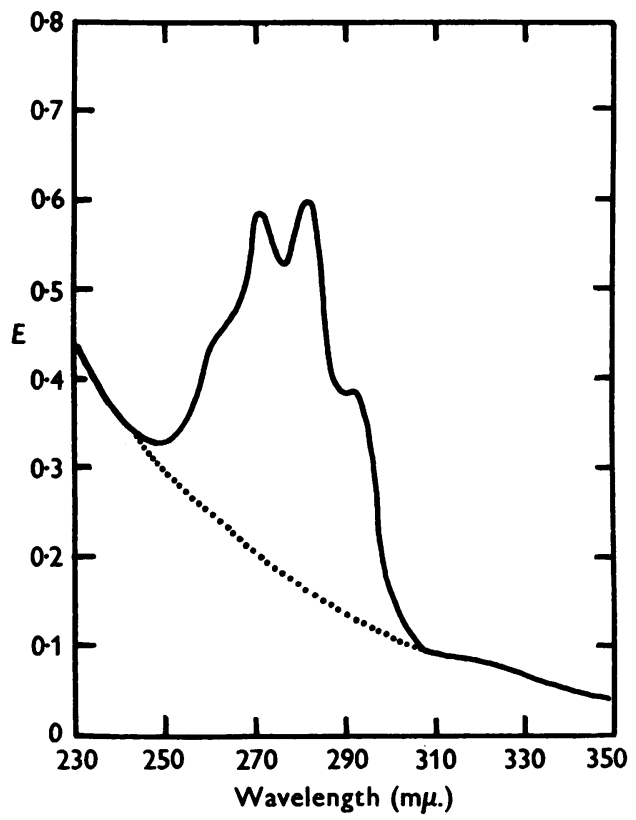

Fig. 1. Absorption spectrum (-) of the unsaponifiable fraction of guinea pig intestine and the interpolated curve $(. .$.$) representing irrelevant absorption.$

spectrum of provitamin $D_{3}$ is clearly shown by the total unsaponifiable fraction; in other cases a preliminary chromatographic separation is desirable. The spectrum of pure 7-dehydrocholesterol (or of other provitamins such as ergosterol) shows only very weak absorption at wavelengths shorter than $230 \mathrm{~m} \mu$. or longer than $300 \mathrm{~m} \mu$. On the other hand, the spectra of tissue extracts usually exhibit

$\begin{array}{cc}\boldsymbol{E} & \boldsymbol{\lambda} \\ \mathbf{( m \boldsymbol { \mu }} .) \\ 0 \cdot 842 & 289 \\ 0 \cdot 854 & 290 \\ 0 \cdot 889 & 291 \\ 0.930 & 292 \\ 0.971 & 293 \\ 0.997 & 294 \\ 1.000 & 295 \\ 0.989 & 298 \\ 0.930 & 300 \\ 0 \cdot 857 & 310 \\ 0 \cdot 832 & 320 \\ 0.744 & \\ 0.642 & \\ 0.593 & \\ 0.548 & \end{array}$

$\underset{(\mathrm{m} \mu .)}{\lambda}$

$289 \quad 0.537$

$290 \quad 0.539$

$291 \quad 0.560$

2920.573

$293 \quad 0.573$

2940.548

$295 \quad 0.495$

$0 \cdot 226$

$000 \quad 0 \cdot 133$

0.008

0.005

$\dagger E=6 / 7 E_{\max }$ within experimental error.

appreciable absorption on the long-wave side of $300 \mathrm{~m} \mu$. and steeply rising unselective absorption on the short-wave side of $240 \mathrm{~m} \mu$. This indicates that substantially linear $(\lambda / E)$ irrelevant absorption is superimposed on the characteristic selective absorption due to the 7-dehydrosteroid. It is often legitimate to interpolate the irrelevant absorption between 240 and $300 \mathrm{~m} \mu$. (Fig. 1). By reading off the 'irrelevant' absorption at $281.5 \mathrm{~m} \mu$. it is possible to correct

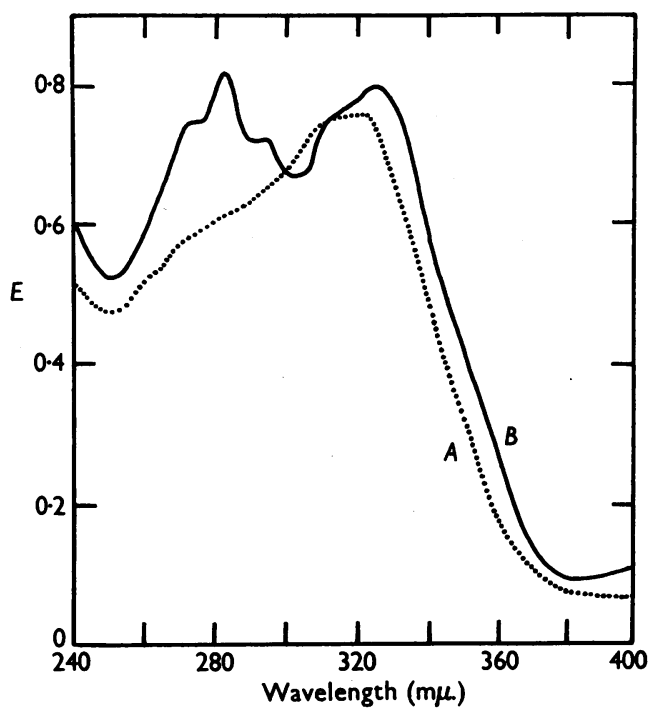

Fig. 2. Absorption spectra of the unsaponifiable fractions of guinea pig livers. $A$, controls; $B$, animals sacrificed $19 \mathrm{hr}$. after dosing with $0.25 \mathrm{~g}$. cholesterol.

the gross reading and arrive at an approximate intensity for the 7-dehydrosteroid contribution. The correction procedure devised by Morton \& Stubbs (1946, 1948), primarily for vitamin A determinations, was applied to the problem of determining ergosterol by Stubbs \& Shakir (1948). For pure 7-dehydrocholesterol the intensity of absorption at 277 and 283.75 $\mathrm{m} \mu$. is $6 / 7$ that at $281.5 \mathrm{~m} \mu$. (Table 2). When an 
observed curve is made up of a component due to the 7 dehydrosteroid and a component exhibiting linear (irrelevant) absorption between 277 and $284 \mathrm{~m} \mu$., then the corrected contribution at the maximum is given by the expression:

$$
E_{\text {corr. }}=7\left(E_{2}-\frac{1}{8} E_{1}-\frac{2}{3} E_{3}\right) \text {, }
$$

where $E_{1}, E_{2}$ and $E_{3}$ are the observed extinctions at 277, 281.5 and $283.75 \mathrm{~m} \mu$. respectively.

Over a wide range of samples the Morton-Stubbs method leads to a value for the irrelevant absorption agreeing very closely with the interpolated value (e.g. falling on the broken line, as in Fig. 1). Occasionally the method is inapplicable because the irrelevant absorption is not linear; this sometimes happens when the correction is obviously quite small, but in other instances the material needs to be subjected to chromatography.

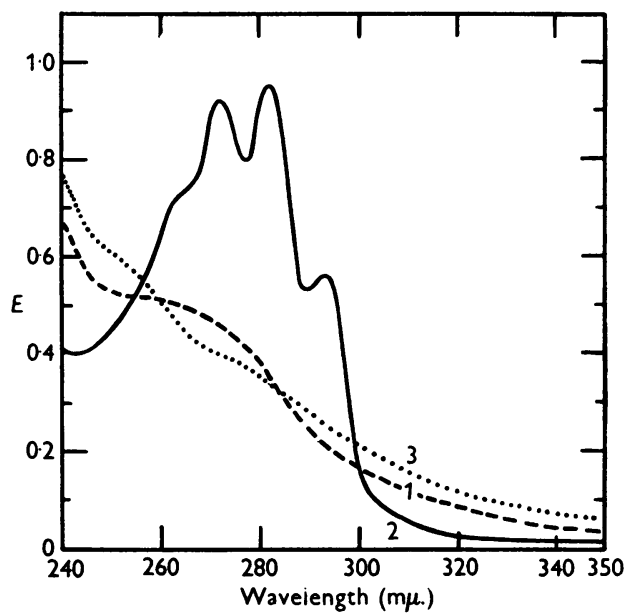

Fig. 3. Typical ultraviolet absorption spectra of the chromatographic fractions of the unsaponifiable matter from the small intestines of guinea pigs. Fraction 1, 'carotene' and sometimes vitamin $\mathbf{A}$ and a substance exhibiting a maximum at $270 \mathrm{~m} \mu$.; fraction 2, sterols; fraction 3, xanthophylls.

A special problem may arise with liver fractions in which vitamin $A$ and 7-dehydrosteroids are present in spectroscopically equivalent amounts (as in Fig. 2). In such circumstances the absorption of vitamin A between 325 and $380 \mathrm{~m} \mu$. is clearly shown and, from the properties of the pure vitamin (Cama, Collins \& Morton, 1951), the curve can be continued from 325 to $230 \mathrm{~m} \mu$. Subtraction of the whole vitamin A curve from the observed curve may then give a difference spectrum agreeing very well with that of the 7-dehydrosteroid.

\section{Chromatographic separation of the sterol fraction from total unsaponifiable matter}

After systematic trials had been made, the following method was adopted. Standard alumina (Grade ' $O$ ', Peter Spence and Co.) was weakened by stirring in water $(5 \% \mathrm{w} / \mathrm{w})$ under light petroleum. In testing unsaponifiable matter (about $0 \cdot 1 \mathrm{~g}$.) from guinea pig intestine the material, dissolved in light petroleum, was poured on to a column
$(0.15 \times 4 \mathrm{~cm}$.) of weakened alumina and formed at the top a deep-yellow layer. The column was developed with $5 \%$ $(v / v)$ diethyl ether in light petroleum (100 ml.); this sufficed to elute the whole of the yellow pigment (fraction 1). Sterols were eluted by further development with 10, 20 and $30 \%$ $(v / v)$ ether-light petroleum (100 ml. portions in succession). The three portions combined gave fraction 2. Elution with $50 \%$ ether-light petroleum $(20 \mathrm{ml}$.) removed a yelloworange fraction 3. Development rate was increased by air pressure from above. Fig. 3 illustrates the spectra of the fractions. Fraction 1 sometimes exhibited an absorption peak near $270 \mathrm{~m} \mu$. and also contained any vitamin A present in the crude unsaponifiable fraction. Fraction 3 showed absorption in the visible due to 'xanthophylls'.

A number of unsaponifiable fractions from guinea pig intestines were examined spectroscopically before and after adsorption. There was an apparent loss of about $15 \%$ of the 7-dehydrosteroid as a result of chromatography, but at present the choice lies between a good approximation and no result at all. About $75 \%$ of the crude unsaponifiable matter (intestine) was recovered in the three fractions and fraction 2 (sterols) accounted for roughly $60 \%$ of the whole. For guinea pig liver the recovery in the three fractions accounted for about $62 \%$ of the crude extract and the sterol fraction amounted to $53 \%$ of the total unsaponifiable matter (average of five tests). The nature of the material retained on the column has not been pursued in the present study.

\section{RESULTS}

Table 3 shows that 7-dehydrocholesterol is not an invariable congener of cholesterol in animal tissues, although it is quite possible that if sufficiently large samples were recrystallized it could be detected in most. The 7-dehydrosteroid bands are shown very clearly in the unsaponifiable fractions obtained from the small intestines of cattle, guinea pigs and rats. Hitherto, the provitamin D has been regarded as mainly a constituent of skin, but in the guinea pig the small intestine is undoubtedly the tissue with the greatest amount.

The spectrum of unsaponifiable matter from guinea pig bile shows a broad adsorption band between 265 and $278 \mathrm{~m} \mu$., and the curves for the unsaponifiable matter from rat and guinea pig blood are similar. Sterol fractions obtained from the unsaponifiable part of rat blood by crystallization at $0^{\circ}$ from a small volume of methanol, showed the 293, 281.5 and $271.5 \mathrm{~m} \mu$. bands, and earlier experience in this laboratory with recrystallized sterols from ox blood is in full accord.

In order to ascertain whether the 7-dehydrosterol in guinea pig intestine is free or esterified the washed small intestines of two animals were studied. The following details refer to the findings in Table 4.

The total lipid $(0 \cdot 339 \mathrm{~g}$.) was dissolved in ethanol (100 ml.). One-half $(50 \mathrm{ml}$.) was reduced to dryness and the residue redissolved in ethanol (20 ml.). Cholesterol was determined gravimetrically as digitonide on two $10 \mathrm{ml}$. portions. The filtrate (containing excess digitonin) was tested for sterol by the Liebermann-Burchard reaction, for esterified cholesterol 
Table 3. Distribution of provitamin $D_{3}$ (7-dehydrosteroid absorption) in animal tissues

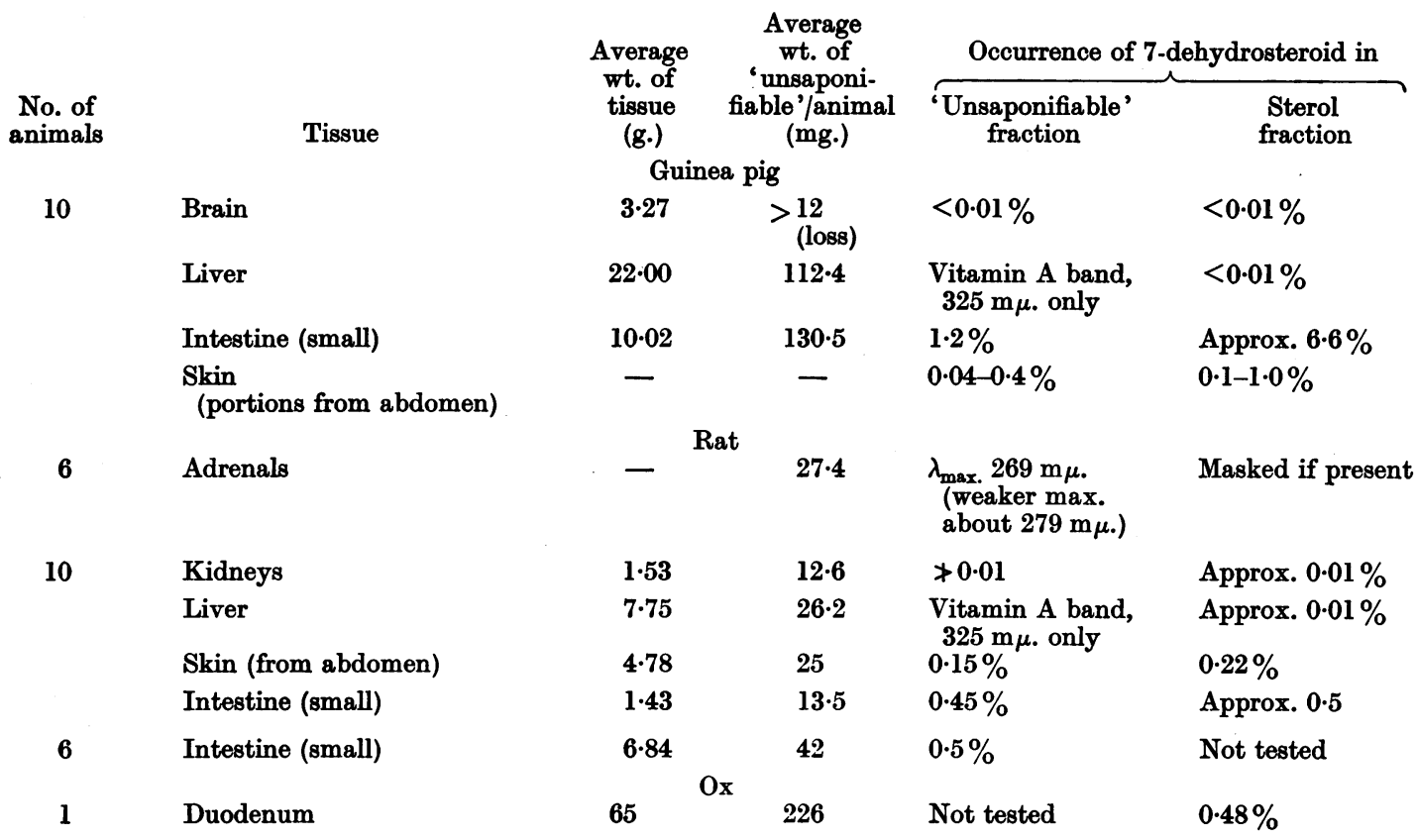

Table 4. Composition of washed guinea pig intestine

(Two animals fasted, overnight. Weights 735, 740 g.)

Lipid from small intestine per animal (g.)*

Unsaponifiable fraction per animal (g.)

7-Dehydrosteroid (percentage of 'unsaponifiable')

Total cholesterol (percentage of 'unsaponifiable')

Esterified cholesterol in lipid

Esterified 7-dehydrosteroid

Not detected

* Tissues pooled.

Table 5. Distribution of 7-dehydrosteroid in adult albino guinea pig intestine (Animals weighed 700-900 g.; fasted 1 day.)

Entire small intestine $(A)$ $E$ and $F$ (average)
(a) Duodenum
(b) Upper ileum
(c) Lower ileum

Mucosa (average) Muscle (average)

\section{Unsaponifiable
fraction} (g.)

(g.)

Guinea pigs $A, E$ and $F$

$15 \cdot 74$

$18 \cdot 26$

0.057

0.074

Guinea pig $B$

$\begin{array}{ll}0.85 & 0.0097(1.14 \%) \\ 5.83 & 0.0164(0.28 \%) \\ 3.80 & 0.0228(0.6 \%)\end{array}$

Guinea pigs $C$ and $D$

8.12

$6 \cdot 34$

0.036

0.058
7-Dehydrosteroid as

$\overbrace{\begin{array}{c}\% \text { of } \\ \text { unsaponifiable' }\end{array}}^{\begin{array}{c}\% \text { of wet } \\ \text { tissue }\end{array}}$

$5 \cdot 6 \quad 0.02$

$6 \cdot 1 \quad 0.025$

$2 \cdot 3 \quad 0.03$

$3 \cdot 1 \quad 0 \cdot 01$

$1.6 \quad 0.01$

$9 \cdot 1$

$0.73<0.01$ 
(by saponification followed by adding digitonin to the 'unsaponifiable') and for 7-dehydrosteroid by ultraviolet absorption. All three tests were negative.

A portion (25 ml.) of the remaining half of the total lipid in ethanol was reduced to dryness, weighed and divided into acetone-soluble and acetone-insoluble portions. The phospholipin fraction dissolved in light petroleum exhibited the provitamin absorption spectrum, presumably as a result of co-precipitation of 7-dehydrosteroid and phospholipin. Accordingly, the neutral fat and phosphatide fractions were remixed and the tests for free and combined sterol repeated. The remaining portion $(25 \mathrm{ml}$.) of total lipid solution was saponified, the unsaponifiable matter weighed and the total sterol and 7-dehydrosteroid content determined.

In the two animals considered here $30 \%$ of the 'unsaponifiable' was sterol and about $6 \% 7$ dehydrosteroid.

Table 5 shows the distribution of the provitamin $D_{3}$ along the small intestine of the guinea pig.
Two albino animals on a normal diet (cubes from Lever Bros and Unilever) were killed after a 1-day fast. The small intestine of one animal $(A)$ was saponified in toto; that of the other $(B)$ was divided into three parts: $(a)$ a length of $5 \mathrm{~cm}$. from the pyloric sphincter ('duodenum'), (b) and (c) equal halves of the remainder. Each portion was saponified separately and the unsaponifiable fraction obtained.

The 7-dehydrosteroid is seen to be mainly in the 'duodenum', although (because of the small amount of unsaponifiable matter in the upper ileum) the proportion of selectively absorbing sterol to total unsaponifiable matter is highest in the upper ileum.

Table 5 also shows the distribution across the gut wall.

The small intestines of two guinea pigs $(C$ and $D)$ were washed out, slit open longitudinally and stretched out on a board. The mucosal tissue was scraped off the underlying layer of muscle tissue, using the blunt side of a scalpel blade.

\section{Table 6. Distribution of 7-dehydrosteroid in guinea pig hide}

(Small portions of hide were taken at random from different parts of several animals.)

\begin{tabular}{lccl} 
& Wt. & 'Unsaponifiable' & \\
& $(\mathrm{g})$. & (\% of gross wt.) & \multicolumn{1}{c}{ 7-Dehydrosteroid } \\
Hair & $\mathbf{1 4 \cdot 3}$ & $\mathbf{2 \cdot 3 8}$ & Trace* \\
Cutaneous tissue & $\mathbf{5 6 \cdot 4}$ & $\mathbf{3 \cdot 7 2}$ & $\mathbf{0 \cdot 1 5 \%}$ (of 'unsaponifiable') \\
Subcutaneous muscle & $\mathbf{2 7 \cdot 4}$ & $\mathbf{0 \cdot 1 8}$ & None detected
\end{tabular}

* Revealed only in recrystallized sterol.

Table 7. 7-Dehydrosteroid of guinea pigs (a) in intestine of normal animals of different weights and animals on a 'sterol-free' diet, (b) in intestine and liver of infected animals as compared with normal animals

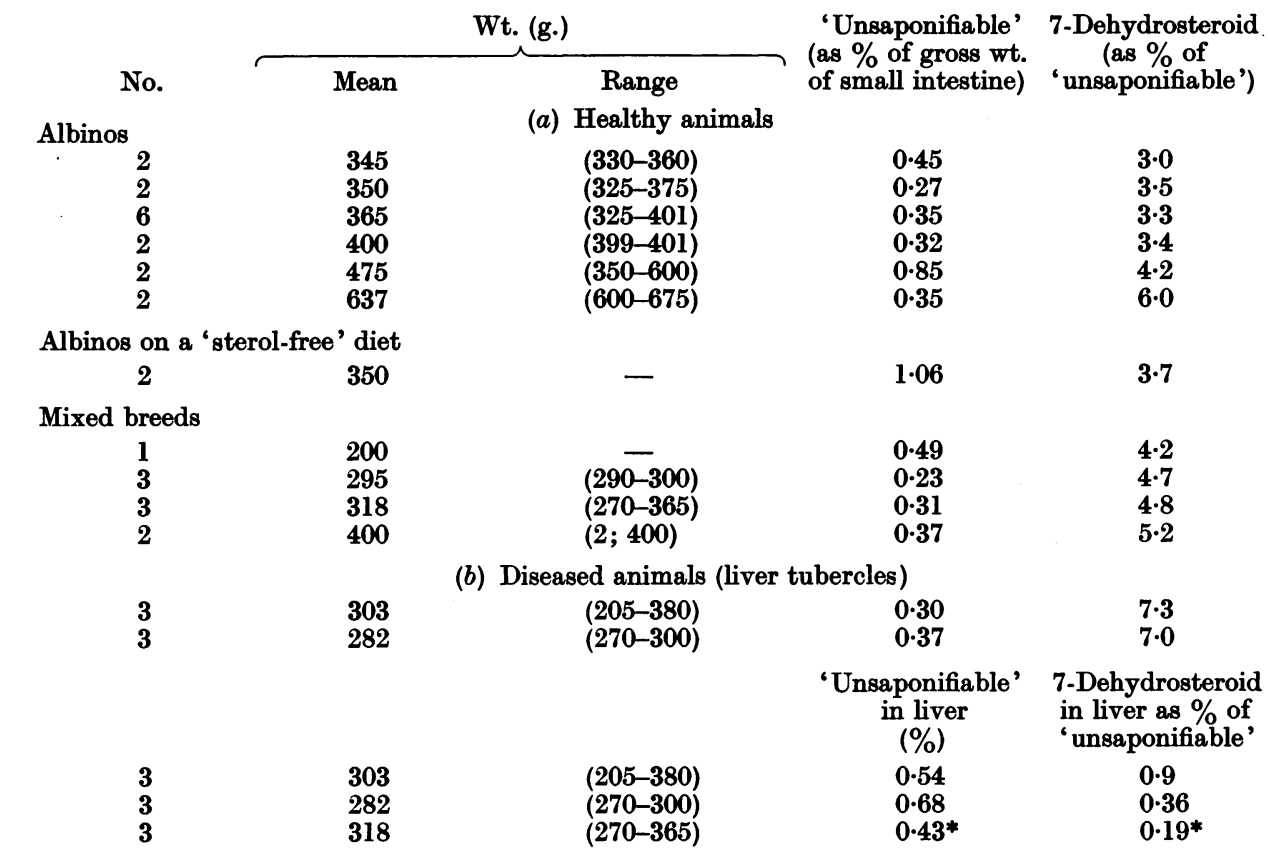

* Livers of normal animals for comparison. 
It is clear that although the separation so obtained is not complete, the 7-dehydrosteroid is almost entirely associated with the mucosal tissue.

As the skin is, next to the small intestine, the richest tissue in 7-dehydrosteroid, portions of guinea pig hide were divided into hair, cutaneous tissue and subcutaneous muscle. Table 6 shows the results of the analyses.

Table 7 shows that the 7-dehydrosteroid content (expressed as percentage of total unsaponifiable matter from guinea pig intestine) increases approximately linearly with the weight of the animal. (In these experiments the weight is taken to be an approximate guide to age.)

A few animals purchased for the work were found on post-mortem examination to have liver tubercles or nodules arising from Pasteurella pseudotuberculosis. These guinea pigs showed a marked increase in the 7-dehydrosteroid content of both liver and small intestine (calculated on the total unsaponifiable fraction) as compared with healthy animals of similar weight kept for some time on a substantially sterol-free diet. This observation, although not strictly germane to the argument, is recorded as a matter of interest.

If the 7-dehydrosteroid absorption spectrum had been due to a dietary constituent, fasting should have resulted in a substantial reduction which did not occur. Again no diminution was observed when guinea pigs or rats were transferred from a normal to a sterol-free diet (Tables 7 and 8). The definition of the three maxima was improved in the fasting animals because of decreased 'irrelevant' absorption attributable to lipid constituents undergoing digestion and absorption.

\section{Characterization of the 7-dehydrosteroid in guinea pig intestine}

(a) Attempted isolation. The selective absorption found in extracts from guinea pig intestine could be due (i) to enzymic dehydrogenation of cholesterol, or (ii) to microbiological synthesis of ergosterol in the intestine, possibly by yeasts.

Boer, Reerink, Wijk \& Niekerk (1936) isolated $0.2 \mathrm{~g}$. of pure 7-dehydrocholesterol from cholesterol of unstated origin, and Windaus \& Bock (1937)

Table 8. Similarity of distribution of 7-dehydrosteroid in the tissues of rats on (a) diet very low in sterols, (b) normal cube diet

\begin{tabular}{|c|c|c|c|c|}
\hline & $\begin{array}{c}\text { Small } \\
\text { intestine }\end{array}$ & Liver & Kidney & $\underset{\text { skin }}{\text { Abdominal }}$ \\
\hline \multicolumn{5}{|c|}{ (a) Animals (five) on a 'sterol-free' diet } \\
\hline $\begin{array}{l}\text { Wt. of tissue (g.) } \\
\text { 'Unsaponifiable' (mg./rat) } \\
\text { 'Unsaponifiable' (mg./g. tissue) } \\
\text { 7-Dehydrosteroid (\% of 'unsaponifiable') }\end{array}$ & $\begin{array}{l}3 \cdot 15 \\
25 \cdot 5 \\
8 \cdot 1 \\
0 \cdot 7\end{array}$ & $\begin{array}{l}9 \cdot 61 \\
11 \cdot 5 \\
1 \cdot 2 \\
\text { Trace* }\end{array}$ & $\begin{array}{l}2 \cdot 03 \\
12 \cdot 0 \\
5 \cdot 9 \\
\text { Trace* }\end{array}$ & $\begin{array}{r}3 \cdot 0 \\
23 \cdot 8 \\
7 \cdot 9 \\
0 \cdot 3\end{array}$ \\
\hline
\end{tabular}

(b) Controls (five animals)

$\begin{array}{cccc}\text { 7-Dehydrosteroid (\% of 'unsaponifiable') } & 0.45 & \text { Trace* } & \text { Trace* } \\ \text { * Dehydrosteroid bands detectable, but the amounts are probably } \ll 0 \cdot 1 \% \text { in all cases. }\end{array}$

$\mathbf{0 \cdot 3}$

Table 9. Conversion of cholesterol to 7-dehydrocholesterol by guinea pigs

\begin{tabular}{|c|c|c|c|c|c|c|c|c|c|}
\hline \multirow[b]{3}{*}{$\begin{array}{c}\text { No. } \\
\text { of } \\
\text { animals }\end{array}$} & \multirow{3}{*}{$\begin{array}{c}\text { Average } \\
\text { wt./ } \\
\text { guinea } \\
\text { pig } \\
\text { (g.) }\end{array}$} & \multirow[b]{3}{*}{$\begin{array}{c}\text { Range } \\
\text { (g.) }\end{array}$} & \multirow[b]{3}{*}{$\begin{array}{c}\text { Time } \\
\text { after } \\
\text { dosing } \\
\text { (hr.) }\end{array}$} & \multicolumn{2}{|c|}{ (Dose 0.25 g.) } & \multicolumn{2}{|c|}{ 7-Dehydrocholesterol in } & & \\
\hline & & & & \multicolumn{2}{|c|}{ Intestinal contents } & \multicolumn{2}{|c|}{ Gut wall } & \multicolumn{2}{|c|}{ Liver } \\
\hline & & & & $\begin{array}{c}\text { (mg./ } \\
\text { animal) }\end{array}$ & $\begin{array}{c}\text { (\% of } \\
\text { 'unsaponi- } \\
\text { fiable)' }\end{array}$ & $\begin{array}{l}\text { (mg./ } \\
\text { animal) }\end{array}$ & $\begin{array}{c}(\% \text { of } \\
\text { 'unsaponi- } \\
\text { fiable') }\end{array}$ & $\begin{array}{c}\text { (mg./ } \\
\text { animal) }\end{array}$ & $\begin{array}{c}\text { (\% of } \\
\text { 'unsaponi- } \\
\text { fiable') }\end{array}$ \\
\hline $\begin{array}{l}6 \\
5 \\
4\end{array}$ & $\begin{array}{l}365 \\
322 \\
343\end{array}$ & $\begin{array}{l}(325-401) \\
(252-400) \\
(310-400)\end{array}$ & $\begin{array}{r}0 \\
5 \\
18\end{array}$ & $\begin{array}{l}\bar{E}^{\mathrm{E}} \\
0.001 \\
0.04\end{array}$ & $\begin{array}{l}\text { p. 1. Albinos } \\
\overline{0.05} \\
0.23\end{array}$ & $\begin{array}{l}1 \cdot 3 \\
3 \cdot 1 \\
1 \cdot 3\end{array}$ & $\begin{array}{l}3 \cdot 3 \\
4 \cdot 4 \\
3 \cdot 1\end{array}$ & $\begin{array}{l}0 \cdot 05 \\
0 \cdot 24 \\
0 \cdot 38\end{array}$ & $\begin{array}{l}0.07 \\
0.48 \\
0.51\end{array}$ \\
\hline \multicolumn{10}{|c|}{ Exp. 2. Albinos } \\
\hline $\begin{array}{l}4 \\
4\end{array}$ & $\begin{array}{l}260 \\
302\end{array}$ & $\begin{array}{l}(4,260) \\
(248-450)\end{array}$ & $\begin{array}{r}5 \\
19\end{array}$ & $\begin{array}{r}\text { Not tested } \\
\text { Not tested } \\
\text { Exp. }\end{array}$ & $\begin{array}{l}\text { Not tested } \\
\text { Not tested } \\
\text { Mixed breec }\end{array}$ & $\begin{array}{l}1 \cdot 7 \\
0 \cdot 9\end{array}$ & $\begin{array}{l}4 \cdot 7 \\
2 \cdot 9\end{array}$ & $\begin{array}{l}0 \cdot 29 \\
0 \cdot 40\end{array}$ & $\begin{array}{l}0.49 \\
0.60\end{array}$ \\
\hline $\begin{array}{l}\mathbf{3} \\
\mathbf{3} \\
\mathbf{3} \\
\mathbf{3}\end{array}$ & $\begin{array}{l}318 \\
298 \\
298 \\
293\end{array}$ & $\begin{array}{l}(270-365) \\
(275-320) \\
(290-300) \\
(250-320)\end{array}$ & $\begin{array}{r}0 \\
3 \\
8 \\
12\end{array}$ & $\begin{array}{l}0.01 \\
0.085 \\
0.087 \\
0 \cdot 11\end{array}$ & $\begin{array}{l}0.15 \\
0.45 \\
0.69 \\
0.46\end{array}$ & $\begin{array}{l}1 \cdot 8 \\
2 \cdot 4 \\
2 \cdot 3 \\
2 \cdot 2\end{array}$ & $\begin{array}{l}4 \cdot 8 \\
6 \cdot 3 \\
4 \cdot 6 \\
5 \cdot 6\end{array}$ & $\begin{array}{l}0.11 \\
0.13 \\
0.28 \\
0.21\end{array}$ & $\begin{array}{l}0 \cdot 19 \\
0.32 \\
0.54 \\
0.38\end{array}$ \\
\hline
\end{tabular}




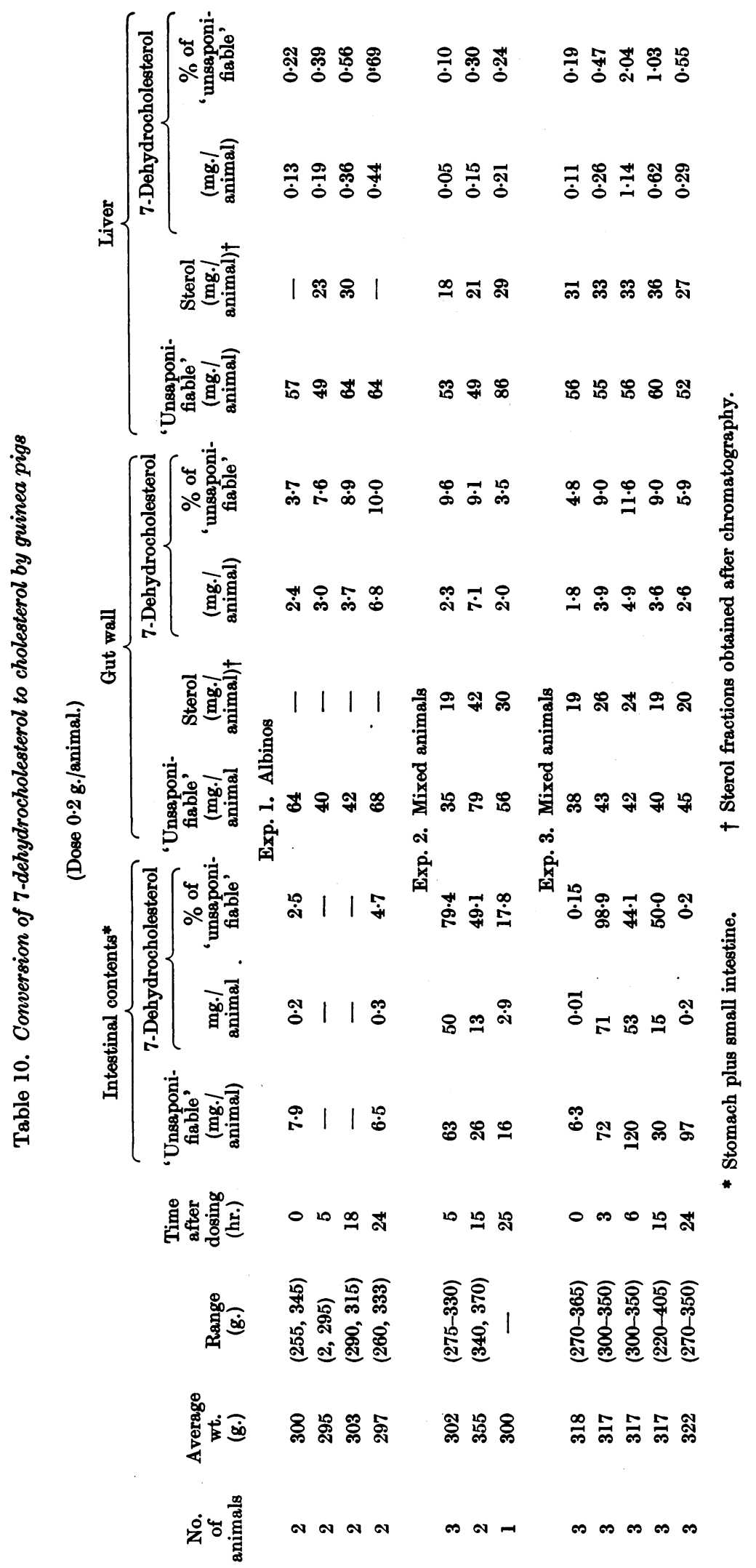


from $100 \mathrm{~kg}$. of hog skin isolated $0.379 \mathrm{~g}$. of 7 dehydrocholesterol of $91 \%$ purity. The amounts of guinea pig intestine available were inadequate for such isolation. Chromatography on alumina $(5 \mathrm{~cm}$.), weakened by addition of water ( $5 \%$ ), applied to $0.231 \mathrm{~g}$. of sterol $\left(E_{1 \mathrm{~cm}, 281.5 \mathrm{~m} \mu .=25.6)}^{\mathrm{1} \%}\right.$ gave a fraction $(A 2)$ eluted by $10 \%$ ether-light petroleum (200 ml.) with $E_{1 \mathrm{~cm} .}^{1 \%} 281.5 \mathrm{~m} \mu .=71$ (49 mg.). A second chromatographic separation on this material gave fraction $B 1$ (eluted by $200 \mathrm{ml}$. of $5 \%(\mathrm{v} / \mathrm{v})$ ether-light petroleum, $\left.E_{1 \mathrm{~cm} .}^{1 \%} 281.5 \mathrm{~m} \mu .=16\right)$ and fraction $B 2$ (eluted by $200 \mathrm{ml}$. of $8 \%(\mathrm{v} / \mathrm{v})$ ether-

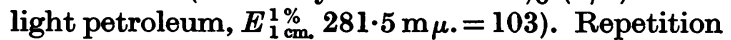
gave $C 3, E_{1 \mathrm{~m} .}^{1 \%} 281.5 \mathrm{~m} \mu .=176$ (2.8 mg.).

Less intensely absorbing fractions were worked up similarly to give another $4 \mathrm{mg}$. of material showing $E_{1 \mathrm{~cm} .}^{1 \%} 281.5 \mathrm{~m} \mu .=165$. The two fractions combined could not be further enriched by chromatography. At this stage experiments were carried out with 7-dehydrocholesterol itself (5 mg.); chromatography of such small amounts resulted in a loss of some $20 \%$ of the original intensity of absorption and it seemed unlikely that further work on a few milligrammes of material could effect further purification. However, the behaviour of the unidentified 7-dehydrosteroid on the column was the same as that of authentic 7-dehydrocholesterol. These experiments did not afford absolute proof that the selectively absorbing sterol of guinea pig intestine is entirely 7-dehydrocholesterol.

(b) In vivo conversion of cholesterol to 7-dehydrocholesterol

(i) Control experiments in which dietary sterol was withheld. Experiments in which the stock diet had been made sterol-free (or practically so) failed to show any diminution in the 7-dehydrosteroid content of the wall of the guinea pig small intestine. This is important because, although sitosterols are not appreciably absorbed by animals (cf. Schönheimer, $1929 a, b, 1931$; experiments on rats), ergosterol can be absorbed more readily. Thus hens can transfer it to the eggs (Page \& Menschick, 1932; Schönheimer \& Dam, 1932; Windaus \& Strange, 1936). Tables 7 and 8 show that for guinea pigs and rats the 7-dehydrosteroid content of the small intestine is not removed (or even appreciably changed) by withholding preformed sterol from the diet for 2 weeks.

Table 9 shows the results with groups of animals given $0.25 \mathrm{~g}$./guinea pig and killed at intervals up to $19 \mathrm{hr}$. after dosing. During the absorption of cholesterol the 7-dehydrosteroid content of the gut wall reached a maximum 3-8 hr. after dosing and then decreased slowly to a normal level. The amount of dehydrosteroid in the liver increased gradually as the cholesterol was absorbed in the gut. The absorption spectra (Fig. 2) of liver extracts of the animal dosed with cholesterol, and of controls, show the effect clearly. Table 10 shows the results of feeding 7-dehydrocholesterol ( $0.2 \mathrm{~g}$./guinea pig). The total steroid of the gut wall shows a definite increase during the main period of absorption (up to $15 \mathrm{hr}$.) which, like the total liver sterol rise, exceeds any increase attributable to the 7-dehydrocholesterol alone.

\section{DISCUSSION}

The 7-dehydrosteroid content of skin varies with the species; thus Windaus \& Bock (1937) found (in the total sterol) $0.16 \%$ for deer skin, $3.6 \%$ for pig skin, $0.18 \%$ for cow skin and $1.5-2.4 \%$ for rat skin. Morton \& Rosen (1949) found a high concentration ( $5 \%$ of the sterol) in the mature ovaries of frogs. Page \& Menschick (1930) found that the sterols from brain contain more 7-dehydrosteroid in foetal life than in adult life. Halibut intestinal sterols have been found in this laboratory to exhibit the 7-dehydrosteroid absorption bands clearly. Rosenberg (1949) found for clams $21.4 \%$ of provitamin $D$ in the visceral sterols and $\mathbf{7 \cdot 8} \%$ in the sterols from the rest of the body.

The present investigation establishes the fact that 7-dehydrosteroid is to be found in the intestinal tissue of rat, ox and guinea pig. In the last-named there is a much greater concentration in the intestine than in the skin, whereas in other species the difference is not striking.

More detailed study of guinea pig small intestine showed a noteworthy absence of esterified cholesterol and the presence of $1 / 15$ to $1 / 5$ of the total sterol as 7-dehydrocholesterol. The provitamin D (expressed as percentage of unsaponifiable fraction) is highest in the upper ileum; practically all of it occurs in the mucosae and very little in the muscle layer of the intestine. Similarly, there is no 7dehydrosteroid in the hair or in the muscle tissue of skin although the true cutaneous layer is relatively well supplied.

The results also show that the 7-dehydrosteroid content of guinea pig intestine tends to increase with increasing size (age?) and more surprisingly with the disease ( $P$. pseudotuberculosis) associated with liver tubercles or nodules.

Attempts to isolate pure 7-dehydrocholesterol from guinea pig intestine were not successful, although a small amount of material containing $60 \%$ was obtained by chromatography. This failure left open the possibility that the unusually high 7-dehydrosteroid ultraviolet absorption in guinea pig intestine fractions had a dietary origin or could have been due to synthesis by yeasts in the alimentary tract. The likelihood of either explanation was diminished by the persistence of the absorption bands at high intensity in animals on a 
practically sterol-free diet and in animals in a postabsorptive state.

The question was settled by the demonstration that orally administered cholesterol is dehydrogenated in the intestine in a manner indicating an equilibrium

$$
\begin{array}{cl}
\text { cholesterol } & \rightleftharpoons 7 \text {-dehydrocholesterol } \\
15 & : 1 \text { approximately }
\end{array}
$$

in both albino and coloured guinea pigs. During absorption the equilibrium is not strictly maintained, and it would appear that all the sterol which enters the gut wall is open to attack by a cholesterol dehydrogenase. The cholesterol so exposed seems to be free and not esterified. Oral administration of 7-dehydrocholesterol is followed by processes of absorption in the intestine and transference to the liver which can only be explained on the basis of a reversal of the dehydrogenation established for cholesterol.

It is noteworthy that the recovery of sterol after feeding cholesterol or 7-dehydrocholesterol is very poor. The rise in liver sterol which might perhaps have been expected, did not in fact occur, and under the conditions of the experiments the liver is able to use or eliminate excess sterol rapidly.

Since the completion of experimental work reported here, Popják \& Beeckmans (1950) have found that in rabbits given $\mathrm{D}_{2} \mathrm{O}$, synthesis of cholesterol takes place more rapidly in the intestinal tissue than in liver. Tuboi (1948) perfused rabbit liver with 7 dehydrocholesterol and noted a rapid disappearance with concomitant formation of cholic and deoxycholic acids. This observation is consistent with our finding that, above a certain low concentration, 7-dehydrocholesterol has a transient existence in liver.

The main conclusion to be reached at this stage is that the animal is not dependent upon dietary provitamin $\mathrm{D}$ but has the power to dehydrogenate cholesterol synthesized in its own body. The small intestine is the main (but not necessarily the only) site of the process.

\section{SUMMARY}

1. The properties of purified 7-dehydrocholesterol have been determined, and a method of correcting ultraviolet absorption curves for irrelevant contributions has been described and applied to sterol fractions prepared by an improved chromatographic method.

2. The distribution of 7-dehydrosteroid has been studied for various ox, rat and guinea pig tissues with the result that the small intestine is shown to be relatively rich, especially in the guinea pig.

3. The 7-dehydrosteroid is mainly concentrated in the mucosae and lamina propria of the absorptive part (duodenum) of the guinea pig intestine; it tends to increase $(a)$ with increasing size, and $(b)$ when the animals exhibit liver tubercles.

4. Cholesterol, administered orally, dissolved in ethyl myristate or oleate, is dehydrogenated in the wall of the small intestine. The dehydrogenase enzyme acts in the reverse sense on orally administered 7-dehydrocholesterol. Much of the administered sterol is metabolized during the first $24 \mathrm{hr}$. after dosing.

We are indebted to the Ministry of Food and the Medical Research Council for financial assistance.

\section{REFERENCES}

Boer, A. G., Reerink, E. H., Wijk, A. van \& Niekerk, J. van (1936). Proc. Acad. Sci. Amst. 39, 622.

Cama, H. R., Collins, F. D. \& Morton, R. A. (1951). Biochem. J. 50, 48.

Heilbron, I. M., Kamm, E. D. \& Morton, R. A. (1926). Chem. \& Ind. 45, 932.

Heilbron, I. M., Kamm, E. D. \& Morton, R. A. (1927). Biochem. J. 21, 78.

Hogness, T. R., Sidwell, A. E. \& Zscheile, F. P. (1937). J. biol. Chem. 120, 239.

Morton, R. A. \& Rosen, D. G. (1949). Biochem. J. 45, 612. Morton, R. A. \& Stubbs, A. L. (1946). Analyst, 71, 348.

Morton, R. A. \& Stubbs, A. L. (1948). Biochem. J. 42, 195.

Page, I. H. \& Menschick, W. (1930). Naturwissenschaften, $18,735$.

Page, I. H. \& Menschick, W. (1932). Hoppe-Seyl. Z. 211, 246.
Popják, G. \& Beeckmans, M.-L. (1950). Biochem. J. 47, 233.

Rosenberg, H. R. (1949). Nature, Lond., 164, 795.

Rosenheim, O. \& Webster, T. A. (1927). Biochem. J. 21, 111.

Schenck, F., Weise, O. \& Buchholz, K. (1936). Ber. dtsch. chem. Ges. 69, 2692.

Schönheimer, R. (1929a). Hoppe-Seyl. Z. 180, 16.

Schönheimer, R. (1929b). Hoppe-Seyl. Z. 185, 119.

Schönheimer, R. (1931). Science, 74, 579.

Schönheimer, R.\& Dam, H. (1932). Hoppe-Seyl.Z.211, 241.

Stubbs, A. L. \& Shakir, M. H. (1948). (Unpublished work.)

Tuboi, S. (1948). J. Jap. Biochem. Soc. $20,139$.

Windaus, A. \& Bock, F. (1937). Hoppe-Seyl. Z. 245, 168.

Windaus, A., Lettré, H. \& Schenck, F. (1935). Liebigs Ann. $520,98$.

Windaus, A. \& Strange, O. (1936). Hoppe-Seyl. Z. 244, 218. 